\title{
Asbestos containing materials in schools of Rome and surrounding area (Italy)
}

\author{
Antonella CAMPOPIANO ${ }^{*}$, Annapaola CANNIZZARO ${ }^{1}$, Angelo OLORI ${ }^{1}$, \\ Federica ANGELOSANTO ${ }^{1}$, Deborah RAMIRES ${ }^{1}$, Fulvio BASILI ${ }^{1}$, Giuseppe GARGARO ${ }^{2}$, \\ Stefano MASSERA ${ }^{2}$, Giuseppina NOVEMBRE ${ }^{2}$, Fulvio CAVARIANI ${ }^{3}$, Federico BRIZI ${ }^{4}$, \\ Marco DI FRANCESCO ${ }^{3}$, Gabriele CASTRI ${ }^{3}$, Andrea CHIODO ${ }^{3}$, Biagio BRUNI ${ }^{5}$ and \\ Sergio IAVICOLI ${ }^{1}$
}

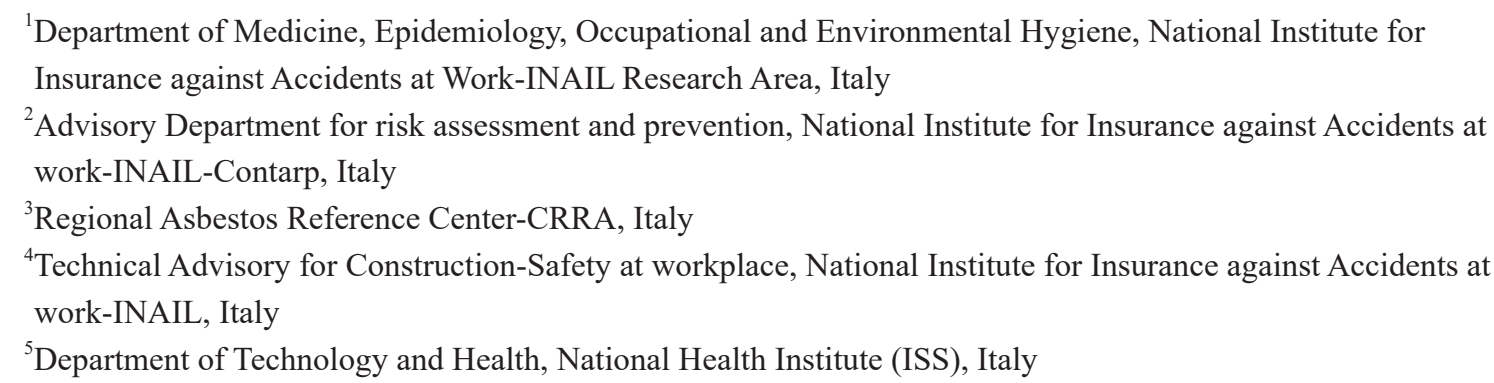

Received February 12, 2021, and accepted April 21, 2021

Published online in J-STAGE September 27, 2021

DOI https://doi.org/10.2486/indhealth.2021-0036

\begin{abstract}
Despite Italy banning use and production of asbestos in 1992, it continues to represent a risk to human health due to its permanence in the places where it was located. The aim of this work is to estimate how many schools in Rome (Italy) have asbestos containing materials (ACM), and to assess whether the location, condition and nature of $\mathrm{ACM}$ can influence the level of risk for student health. 3,672 schools were contacted and 1,451 participated to asbestos survey. 692 bulk samples were collected and analyzed by optical and electron microscope and Fourier transform infrared spectrometer. About 16\% of the surveyed schools had ACM. Most of the ACM were not accessible to students (water tanks, boiler thermal insulations). Asbestos-cement materials and vinyl floor tiles were the most common non-friable materials found in schools and equipment insulation linings and Bunsen burner gauze mats were the friable ACM found in science laboratories. Measures to prevent or reduce asbestos hazards were applied where necessary. This study allowed to develop the awareness of the asbestos health hazard among headteachers and the need to manage these hazards appropriately. It represents the beginning of a larger study leading to ACM national mapping in schools.
\end{abstract}

Key words: Asbestos, Asbestos containing materials, Vinyl floor, Friable materials, Schools, children asbestos exposure, SEM analysis

*To whom correspondence should be addressed.

E-mail address: a.campopiano@inail.it

(C)2021 National Institute of Occupational Safety and Health 


\section{Introduction}

Asbestos was widely used in Italy for building and industrial applications until the late $80 \mathrm{~s}$. The greatest industrial use of asbestos worldwide was in combination with cement, for the construction of a wide variety of products, such as, pipelines or flat and corrugated sheets. Both chrysotile and amphibole (crocidolite and amosite) have been used in asbestos-cement materials produced in Italy until 1986. In that year, the use of crocidolite in asbestos-cement products has been forbidden due to the increased danger of these fibres compared with other varieties of asbestos ${ }^{1)}$. This explains the presence of asbestos-cement sheets containing only chrysotile, introduced on the market after 1986, instead of sheets with both varieties of asbestos (chrysotile and amphibole).

In 1992 the Italian regulation ${ }^{2)}$ banned use and production of asbestos and asbestos containing materials (ACM) but in spite of it, the risk of exposure to asbestos still exists, because most of ACM have not been removed and continue to be located not only in industrial environment, but also in public buildings, such as schools and hospitals.

ACM may constitute a source of airborne asbestos in the environment depending on whether the asbestos is firmly locked inside the material or not.

The presence of asbestos in a building does not indicate that it is a health hazard to the occupants of building. When ACM is in good condition and has no potential to be damaged, it does not give rise to airborne asbestos fibres, and the exposure is unlikely.

A potential health risk to occupants exists when ACM inside the building can be damaged because of maintenance work, repair or vandalism. In this case, fibres can be released into air.

Generally, ACM in buildings are found in three groups: sprayed on ceilings, wall and other surface; insulation on pipes, boiler, tanks, ducts and other systems; and in a variety of other products such as ceiling and floor tiles (miscellaneous materials). ACM belonging to the first two groups are friable materials, that is, they can be crumbled or reduced to powder by hand pressure, as defined by U.S. Environmental Protection Agency ${ }^{3}$. Friable ACM, if disturbed, are dangerous because they can very easily release fibres into environment. In the third group, there are non-friable materials. They are made from a bonding compound with $15-20 \%$ of asbestos. The bonding compound locks asbestos inside the product and generally do not constitute a significant source of airborne asbestos fibres, as long as they remain in good condition. Asbestos-cement materials and asbestos vinyl tiles are a good example of asbestos locked inside the product.

Our focus is on children because children are remarkably vulnerable to both acute and chronic effects of environmental hazards compared to adults ${ }^{4}$. It is known that asbestos exposure is the only established risk factor known to be causally related to mesothelioma and the risk of mesothelioma persists and increases a long time after exposure to asbestos has ended.

Compared to adults, children having a longer life expectancy, have more likely to develop over time asbestos related diseases. Moreover, the children show a physical immaturity, their lung development does not end at birth but continues during adolescence ${ }^{5)}$ and the fibre deposition occurs more rapidly and more abundantly because of their little airways, greater pulmonary ventilation and greater airflow velocity ${ }^{6,7)}$. Behavioral factors can also contribute to increase the risk of adverse effects on child health, in comparison with the adult one. Children often play for a long time on the floor where dust and fibres are deposited and often in environments where damaged ACM are present. This can lead to a greater inhalation of fibres ${ }^{8}$. For the above, it is necessary to pay attention to environments where children live, among which school environment is certainly one of the most important, due to the long time that a child stays at school. In Italy, it is assumed that children spend 13 years at school for at least 30 hours per week for about 35 weeks of the year ${ }^{9)}$.

There are no quantitative data on exposure risk to asbestos fibres in Italian schools. Quantitative asbestos cancer risk assessment is related to quantify the exposure dose and the factors that determine its value, which are intensity, frequency and length of exposure. Until now, the dose-response relations were elaborated using the airborne asbestos fibre concentrations concerning the historical exposure of workers employed in manufacturing process that used asbestos as raw material. The values of these concentrations were very high compared to the current indoor levels, and furnish no useful information in order to elaborate the related risk.

Our previous surveys ${ }^{9)}$ carried out from 1992 to 2002 in 59 primary and secondary schools with ACM showed that the levels of airborne asbestos were lower than detection limit of the analytical procedure used $(0.4 \mathrm{f} / 1)$ in $83 \%$ of the surveyed schools. The release of asbestos fibres into building was negligible also in presence of deteriorated ACM. $14 \%$ of the measurements carried out in the surveyed schools, showed airborne asbestos concentration between 0.7 and 1 f $/ 1.3 \%$ showed an airborne asbestos exposure 
around $2 \mathrm{f} / \mathrm{l}$, corresponding to areas of buildings in which ACM were severely damaged or underwent continuing disturbance.

The incidence of Malignant Mesothelioma (MM) cases in Italy, in different age classes by modality of exposure is reported in the Italian Registry of Mesothelioma (ReNaM), that is an epidemiological surveillance system characterized by a network of regional operating centers established by all 20 Italian regions. The most recent report of the ReNaM identified 27,356 incident cases of mesothelioma from 1993 to $2015^{10)}$. Information on the exposure context was available for 21,387 cases and $70.0 \%$ experienced occupational exposure (certain, probable, possible). Among these, 91 cases of school teachers and school staff throughout Italy are reported ${ }^{10)}$

Mortality from MM in $\leq 50$ years old people, considering the long latency, is likely related to asbestos exposure in childhood $^{11)}$. The analysis of early mortality from MM, reported in the study of Fazzo et al. 2020, showed that in Italy, in 2003-2016 period, 487 people $\leq 50$ years old died from $\mathrm{MM}$, representing $2.5 \%$ of all deaths from $\mathrm{MM}$ in the same period. The analyzed cases were young people who lived where former asbestos-cement plants, shipyards, and a quarry contaminated by fluoroedenite fibres were present and likely environmental asbestos exposure was higher than any exposure in the schools. Until sure scientific data are acquired whether low airborne asbestos fibre concentrations have hazardous effects or not, the exposure assessment of children to asbestos in school building is of great concern.

The aim of this work is to estimate how many schools in Rome and surrounding area (Italy) have ACM, and to assess whether the location, condition and nature of ACM can influence the level of risk for student health.

\section{Subjects and Methods}

In 2015, the Italian Institute for Insurance against Accidents at Work (INAIL) with the Italian National Health Institute (ISS, the leading technical-scientific body of the Italian National Health Service. The Institute is under the supervision of the Ministry of Health) and Italian Regional Center of Asbestos of Lazio Region (RCA, identified as regional center specialized in the risk assessment of human asbestos exposure) contacted 3,672 school buildings (preschool, primary school, secondary school and high school), located in Rome and surrounding area in order to know if the schools had ACM.

A website was created and a login and a password were provided to each headteacher. They could access to web page and fill out a questionnaire regarding to 1) basic building data: identification of school building (school name, municipality and zip code); 2) main data of school headteacher (name, surname, phone number and email address); 3) specific data, among which: number of students attending the school; number of teachers; number of school staff; 4) information relating to the presence of ACM: year of construction of the building; presence of ACM in the school; ACM type; ACM location; existence of an asbestos monitoring program; request for a site inspection.

The working group (INAIL, ISS, RCA) conducted an asbestos survey in school buildings. The first step of the survey was the visual inspection to detect ACM and suspect ACM based on material age and professional experience. The inspection and the identification of ACM were conducted according to the criteria established by the Italian Ministerial Decree 19942). During the survey, the condition of all materials was assessed. Assessment involved the evaluation of a number of factors, including physical properties, among which friability of material, vulnerability to damage and accessibility of ACM.

During the course of the site inspection, representative bulk samples of material were collected for asbestos analysis. Moreover, photographic documentation of every site was acquired. The number of samples by ACM type collected in the schools ranged from 0 (schools with presumed $\mathrm{ACM}$ ) to 5 (schools with the following ACM type: roofing, chimneys, floor, boiler lining, and water tank). The number of samples taken per school was highly variable because it depended on ACM type. An average of 3-4 samples were taken per school. Overall, 692 bulk samples were collected. All samples were analyzed in the laboratories of the working group, qualified for asbestos analysis according to the Italian Ministry of Health Decree ${ }^{12}$.

The instrumentation used for determining presence or absence of asbestos was: stereomicroscope (LEICA M205C), phase contrast optical microscope (PCOM, LEICA), scanning electron microscope (SEM, LEO 440) equipped with energy-dispersive X-ray analysis (EDS, Oxford Instrument INCA) and Fourier transform infrared spectrometer (FTIR, Spectrum one, Perkin Elmer).

The analysis of asbestos is a complex task which involves different approaches depending on the characteristics of the bulk samples. The coupling of more analytical techniques is the key for a good asbestos analysis.

The analytical scheme followed in this study was:

1) observation of the sample at low-powered stereo microscope (e.g., $\times 8$ to $\times 40$ magnification) for the initial 
search for fibres;

2) PCOM analysis is then needed;

2a) when there are fibres, they are identified using the appropriate Cargille refractive index liquid; and comparing the results with techniques auxiliary to microscopy such as FTIR. Where necessary, disagreements between results of two techniques are resolved by analyzing the sample with SEM;

2b) when no fibre is observed, the sample needs to be analyzed by SEM.

Examination of a fibre sample by SEM allows the detection of much smaller fibres than light microscopy. Some samples, such as vinyl floor tiles may contain fibres too small to be resolved by PCOM, thus this ACM type is observed by SEM.

The detection limit of these techniques is dependent on the type of sample (matrix components, texture, etc.), on the preparation of the sample (homogeneity, grain size, etc.). A detection limit of $1 \%$ is feasible given certain sample characteristics in light microscopy, but could be as low as $0.5-0.25 \%$ depending on the skill of analyst. The performance of the light microscopy is analyst dependent. For this reason, the analyst must have adequate training in sample preparation, and experience in the identification of asbestos in samples.

SEM analysis is a reliable method for the detection and positive identification of asbestos in some bulk building materials, both friable and non-friable. The method is particularly applicable to bulk materials that contain a large amount of interfering materials that can be removed by ashing and/or dissolution and contain asbestos fibres that are not resolved by PCOM techniques. The detection limit is around $0.01 \%{ }^{12}$. It should be noted that for Italian current legislation a material "not contained asbestos" or "asbestos-free" is a material in which no fibre should be detected under scanning electron microscope ${ }^{13)}$.

Twenty-five air samplings were carried out in 5 schools, using static samplers (Analitica Airflow 300T) with a flow rate of 10-12 1/min for sampling variable air volumes but not less than 3,000 1. The airborne particulate was sampled using $25 \mathrm{~mm}$ diameter and $0.8 \mu \mathrm{m}$ porosity polycarbonate membrane filters. A quarter of each filter was mounted on an aluminum stub and coated with a thin layer of gold; SEM analysis allowed the identification of asbestos fibres. The concentrations of respirable airborne asbestos fibres were evaluated on the ground of the definition of a respirable fibre: object of length greater than $5 \mu \mathrm{m}$, diameter less than $3 \mu \mathrm{m}$ with a length to diameter ratio (aspect ratio) greater than 3:1.

Twelve settled dust samples by adhesive tape were collected in 3 schools, and observed by SEM.

A final report was drafted for each studied school building, showing all details of the site inspection, the analytical results of the bulk samples collected, and providing advice on the duties under the national law to manage asbestos hazards appropriately. The report was sent to respective headteacher.

\section{Results}

The completed questionnaires were 1,451 , of which $26 \%$ was referred to preschool buildings, $24 \%$ to primary school (a)

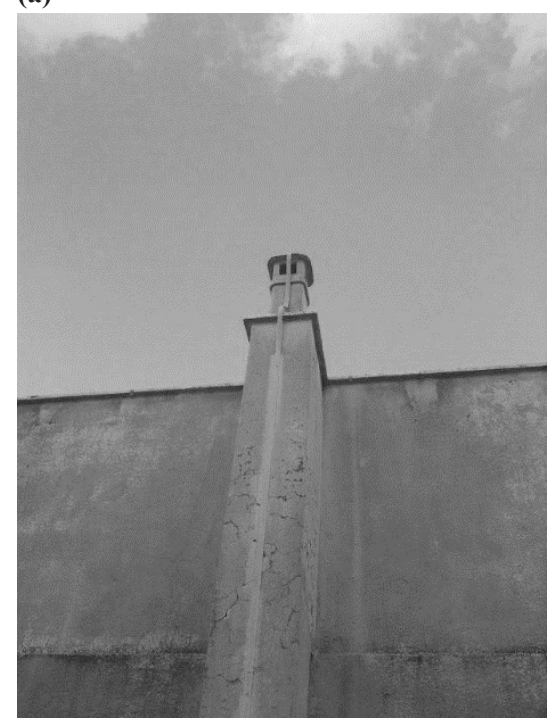

(b)

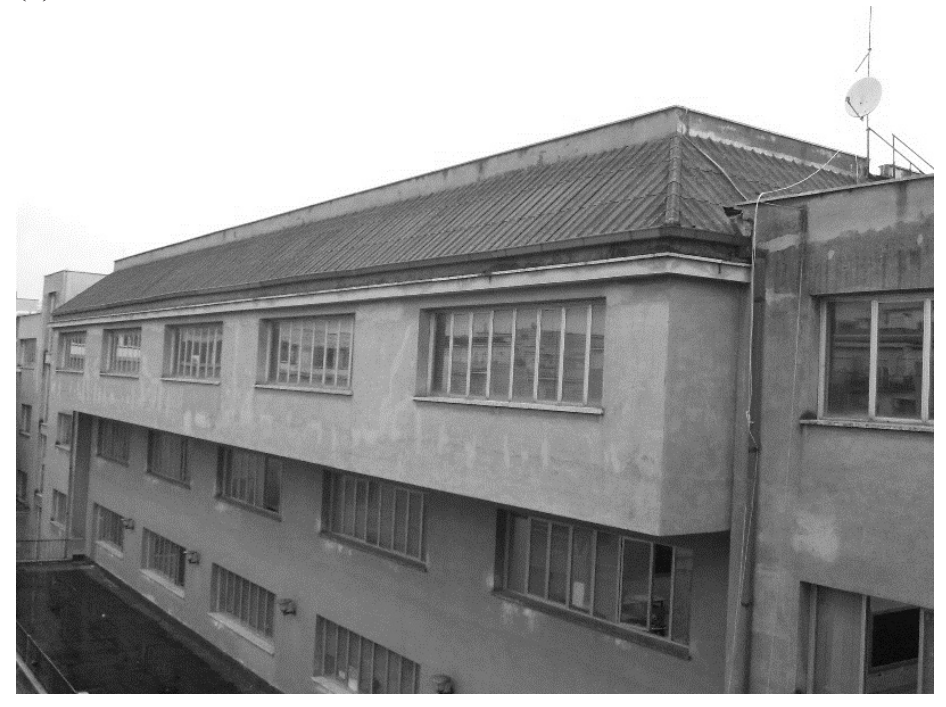

Fig. 1. Example of presumed ACM: thermal system insulation (a) and roofing (b) in buildings constructed no later than 1980. 
buildings and $50 \%$ to secondary school buildings. The analysis of the questionnaire data showed that most buildings was built between 1950 and 1980, a time when asbestos was added to every kind of building material to increase durability and fire resistance.

Headteachers confirmed the presence of ACM in 52 school buildings without requesting an asbestos survey, while a site inspection was requested in 233 school buildings to confirm or exclude the presence of ACM.

167 surveyed schools had ACM and 16 schools had "presumed ACM". In analogy with the OSHA standards ${ }^{14)}$, the term "presumed ACM" refers to pipes, boilers, tanks, flues found in buildings built later than 80 s. Clearly, the term "presumed" was introduced because many of these materials, being inaccessible, were not sampled and analyzed to verify the presence of asbestos. Examples of presumed ACM are shown in Fig. 1.

Referring to the total number of schools participating in this project $(1,451): 15 \%$ had ACM (corresponding to 219 schools), 1\% had "presumed ACM" and 84\% had no ACM.

All 219 schools had non-friable ACM, and among these 40 schools also had friable ACM.

The analysis of 692 bulk samples of the suspected materials permitted to verify the presence of asbestos and identify the type of asbestos in 333 samples.

About $83 \%$ of the ACM found in the school buildings were non-friable materials that is materials made from a bonding compound (such as cement) mixed with a small proportion (usually less than $15 \%$ ) of asbestos. These materials cannot be crumbled, pulverized or reduced to powder

Table 1. Non-friable ACM found in school buildings

\begin{tabular}{|c|c|c|c|}
\hline Type of non-friable ACM & Location & $\begin{array}{l}\text { Asbestos content* } \\
\text { (asbestos type) }\end{array}$ & $\begin{array}{l}\text { Probability to release fibres } \\
\text { into air }\end{array}$ \\
\hline Water tanks & Loft & $\begin{array}{l}10-15 \% \text { asbestos } \\
\text { (chrysotile and crocidolite) }\end{array}$ & $\begin{array}{l}\text { Medium/high (if disturbed, } \\
\text { damaged, or when they become } \\
\text { weathered with age). }\end{array}$ \\
\hline Flues and chimneys & External roof & $\begin{array}{l}10-15 \% \text { asbestos } \\
\text { (chrysotile and crocidolite) } \\
\text { (note: about } 50 \% \text { samples } \\
\text { collected had only chrysotile) }\end{array}$ & $\begin{array}{l}\text { Medium/high (if disturbed, } \\
\text { damaged, or when they become } \\
\text { weathered with age). }\end{array}$ \\
\hline Asbestos cement roofs & $\begin{array}{l}\text { Exterior roofing of } \\
\text { school }\end{array}$ & $\begin{array}{l}10-15 \% \text { asbestos } \\
\text { (chrysotile and crocidolite) } \\
\text { (note: about } 20 \% \text { samples } \\
\text { collected had only chrysotile) }\end{array}$ & $\begin{array}{l}\text { Medium/high } \\
\text { (if disturbed, damaged, or when } \\
\text { they become weathered with } \\
\text { age). }\end{array}$ \\
\hline Asbestos vinyl floors & $\begin{array}{l}\text { Classrooms, staffrooms, } \\
\text { gyms, corridors, lunch } \\
\text { rooms }\end{array}$ & $10-15 \%$ chrysotile & $\begin{array}{l}\text { Very low (except when they are } \\
\text { many damaged). }\end{array}$ \\
\hline Downpipes and gutters & $\begin{array}{l}\text { External walls of } \\
\text { building }\end{array}$ & $\begin{array}{l}10-15 \% \text { asbestos } \\
\text { (chrysotile and crocidolite) }\end{array}$ & $\begin{array}{l}\text { Medium/high (if disturbed, } \\
\text { damaged, or when they become } \\
\text { weathered with age). }\end{array}$ \\
\hline $\begin{array}{l}\text { Acoustic cement panels } \\
\text { (partition walls) }\end{array}$ & $\begin{array}{l}\text { Gyms, music classroom, } \\
\text { auditorium }\end{array}$ & $\begin{array}{l}10-15 \% \text { asbestos } \\
\text { (chrysotile) }\end{array}$ & $\begin{array}{l}\text { Medium/high (if disturbed, } \\
\text { damaged, or when they become } \\
\text { weathered with age). }\end{array}$ \\
\hline $\begin{array}{l}\text { Other } \\
\text { (Asbestos cement flower pots; } \\
\text { Asbestos cement walls ) }\end{array}$ & External building & $10-15 \%$ chrysotile & $\begin{array}{l}\text { Medium/high } \\
\text { (if disturbed, damaged, or when } \\
\text { they become weathered with } \\
\text { age). }\end{array}$ \\
\hline
\end{tabular}

*The concentration of asbestos are the estimates of the average concentrations of asbestos in the materials as reported by the Health Ministry Decree $(1994)^{12)}$. 
by hand pressure.

Tables 1 and 2 show non-friable and friable ACM found in the surveyed schools respectively. ACM location, that is where the ACM was found in a school building, the asbestos content suggested by Italian Ministerial Decree 1994 ${ }^{12}$ and the ease of the material to release fibres into the environment are added in tables. Table 2 also shows the number of friable ACM by type. The number of non-friable ACM by type is deducible from Fig. 2 that shows the percentage of six different types of non-friable ACM identified in the schools on a bar chart.

Asbestos-cement materials and vinyl floor tiles (included backing and glue) were the most common non-friable ACM found in school buildings. Fig. 3 and 4 show some of non-friable ACM in the schools.

Microscopic analyses of bulk samples confirmed that only chrysotile fibres were present in vinyl-asbestos tiles (Figs. 5a, 5b). FTIR analysis, widely used for ACM analysis, is complementary to PCOM analysis especially for detection of asbestos in vinyl floor tiles when in PCOM a suspected fibre is observed. In Fig. 6 are shown the spectra of two samples of vinyl tiles (with and without chrysotile respectively). The samples were detected with diffuse reflectance.

In Italian buildings, chrysotile asbestos has been the most common form of asbestos found in roofs since the 1980s due to restrictions on the marketing and use of crocidolite and of products containing crocidolite ${ }^{1)}$. In surveyed school buildings, crocidolite together with chrysotile were identified in about $80 \%$ of roofing samples collected (Figs. $7 \mathrm{a}, 7 \mathrm{~b})$ confirming the year of construction of the building declared on the questionnaire (1950-1980). The number of non-friable ACM containing chrysotile and crocidolite was 199 (corresponding to about $72 \%$ of non-friable ACM collected); 47 friable ACM samples contained chrysotile and amosite as amphibolic asbestos (Table 2).

Total, average and maximum amount of non-friable ACM found in the schools was roughly estimated according to ACM type (Table 3). The size of the water tanks found in schools varied widely. An average weight of $70 \mathrm{~kg}$ was considered for a medium-sized tank, taking into account that $1 \mathrm{~m}^{2}$ of asbestos-cement weighs over $10 \mathrm{~kg}^{15}$. About roofs, we considered an average weight of $1 \mathrm{~m}^{2}$ of roofing equal to $13 \mathrm{~kg}$, having found both asbestos flat and corrugated roofing ${ }^{15)}$. Flues and chimneys were not included in the count due to the difficult to quantify; thus, the amount showed in Table 3 is underestimated. The visual inspection allowed to classify the asbestos-cement materials into three classes: intact materials not susceptible to damage; materials susceptible to damage; damaged materi-

Table 2. Friable ACM found in school buildings

\begin{tabular}{|c|c|c|c|}
\hline $\begin{array}{c}\text { Type of friable ACM } \\
\text { (number of collected samples) }\end{array}$ & Location & $\begin{array}{l}\text { Asbestos content* } \\
\text { (Asbestos type) }\end{array}$ & $\begin{array}{c}\text { Probability to release fibres into } \\
\text { air }\end{array}$ \\
\hline $\begin{array}{l}\text { Boiler lagging } \\
\text { (28 samples) }\end{array}$ & Boiler rooms & $\begin{array}{c}\text { 80-100\% asbestos } \\
\text { Chrysotile and amosite } \\
\text { were used. } \\
\text { Blankets, felts, papers, } \\
\text { tapes and ropes were } \\
\text { usually } 100 \% \text { chrysotile. }\end{array}$ & $\begin{array}{c}\text { High probability to release fibres } \\
\text { in air if the lagging is not } \\
\text { encapsulated }\end{array}$ \\
\hline $\begin{array}{l}\text { Equipment insulation linings } \\
\qquad(19 \text { samples })\end{array}$ & $\begin{array}{c}\text { Science classrooms } \\
\text { (Laboratory machines, such as } \\
\text { ovens and centrifuges) }\end{array}$ & $\begin{array}{l}100 \% \text { asbestos } \\
\text { (chrysotile and amosite) }\end{array}$ & $\begin{array}{l}\text { High probability to release fibres } \\
\text { in air }\end{array}$ \\
\hline $\begin{array}{l}\text { Bunsen burner gauze mat } \\
\qquad(10 \text { samples })\end{array}$ & Science classrooms & $70-80 \%$ chrysotile & $\begin{array}{c}\text { Medium probability to release } \\
\text { fibres in air. } \\
\text { (Gauze mats used under } \\
\text { Laboratory fume hoods). }\end{array}$ \\
\hline $\begin{array}{c}\text { Insulation lining of fire-rated } \\
\text { door } \\
(1 \text { sample })\end{array}$ & Corridor & Until to $100 \%$ chrysotile & $\begin{array}{l}\text { High probability to release fibres } \\
\qquad \text { in air }\end{array}$ \\
\hline
\end{tabular}

*The percentages of asbestos are the estimates of the average concentrations of asbestos in the materials as reported by the Health Ministry Decree $(1994)^{12)}$ 
als. Approximately, the percentages of asbestos-cement material type according to damage class are shown in Table 4. No intact asbestos-cement material was found. All water tanks, flues and chimneys found were damaged; while all acoustic panels used in gyms, auditorium for internal partition walls were not particularly damaged but can be easily disturbed.

Finally, only one school was a prefabricated building and had external asbestos-cement sandwich prefabricated panels. The asbestos detected was chrysotile and the sandwich panel was filled with man-made mineral fibres.

About friable ACM, a fire-rated door with lining of chrysotile was found in a school building (Fig. 8a). In science laboratories of 9 schools, some laboratory machines, such as ovens and centrifuges included asbestos as internal insulating material (Fig. 8b). In these laboratories, a large number of Bunsen burner gauze mats containing asbestos were found (Fig. 9a). The gauze mats, placed on tripods above Bunsen burners have a white heat-resistant pad at the center. The microscopic analysis showed the presence of chrysotile in the heat-resistant material. This material being soft and crumbly was classified as friable.

Fortunately, the most commonly found form of friable ACM was as thermal insulation on pipes and boilers in rooms accessible only to technical personnel. The type of asbestos detected in this friable ACM was chrysotile (Fig. 9b).

Twenty-five air samplings were carried out in the class-

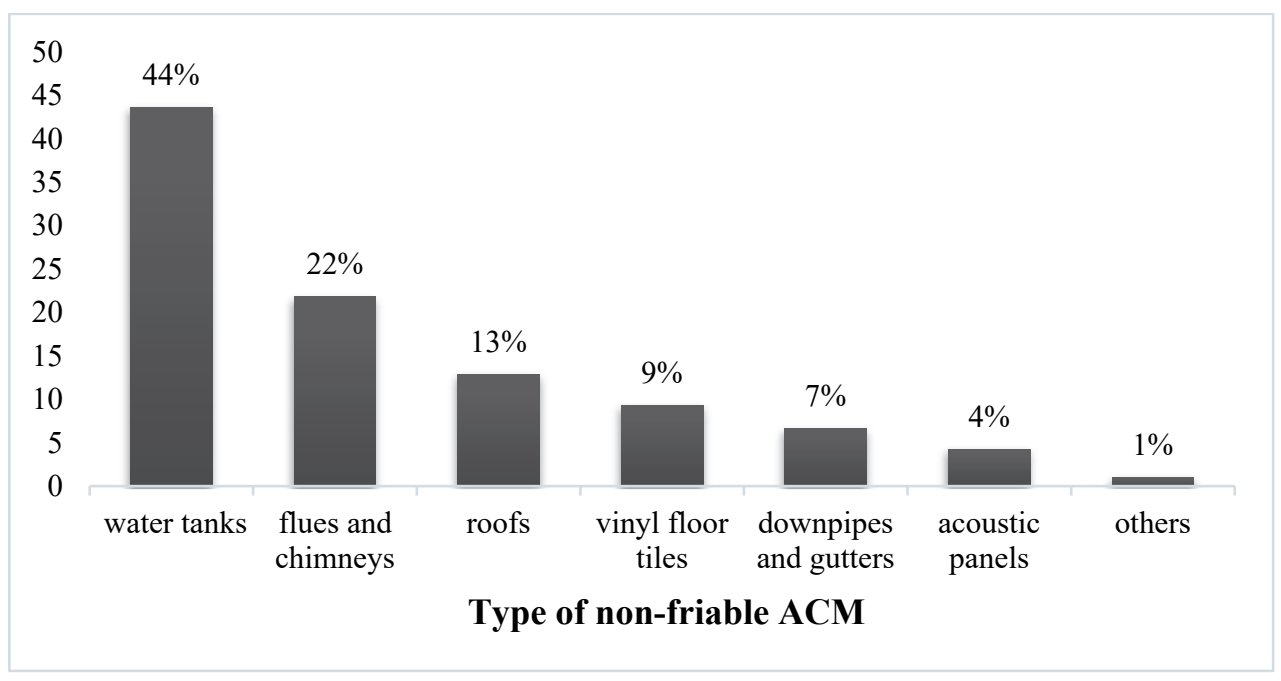

Fig. 2. Numerical proportion of the non-friable ACM found in the schools of Rome and surrounding (total number of non-friable $\mathrm{ACM}$ is 275).

(a)

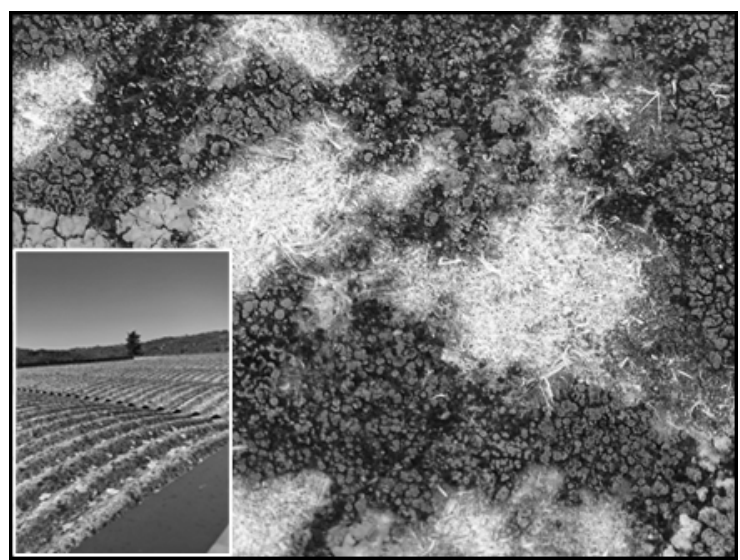

(b)

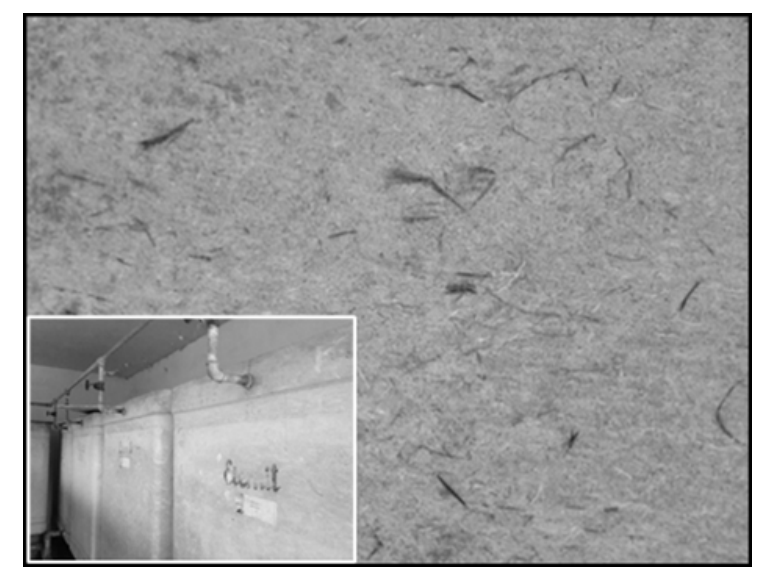

Fig. 3. Examples of non-friable ACM in the schools. Asbestos cement roofing and surface corrosion which leads to the formation of a surface layer rich in easily released fibres into the environment (a). Water thanks in asbestos-cement. Note the signature "Eternit", the first worldwide industrially manufactured material and detailed image of presence of zones where asbestos fibres are surfacing (b). 
(a)

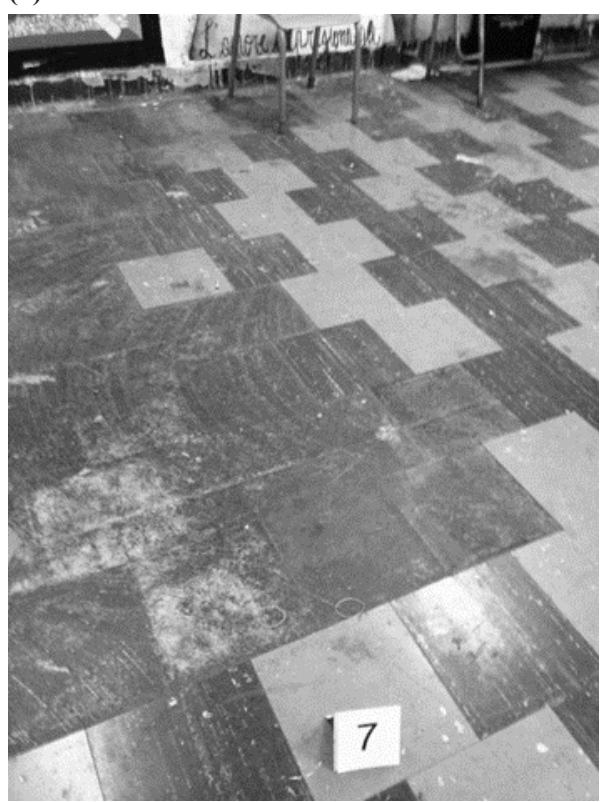

(b)

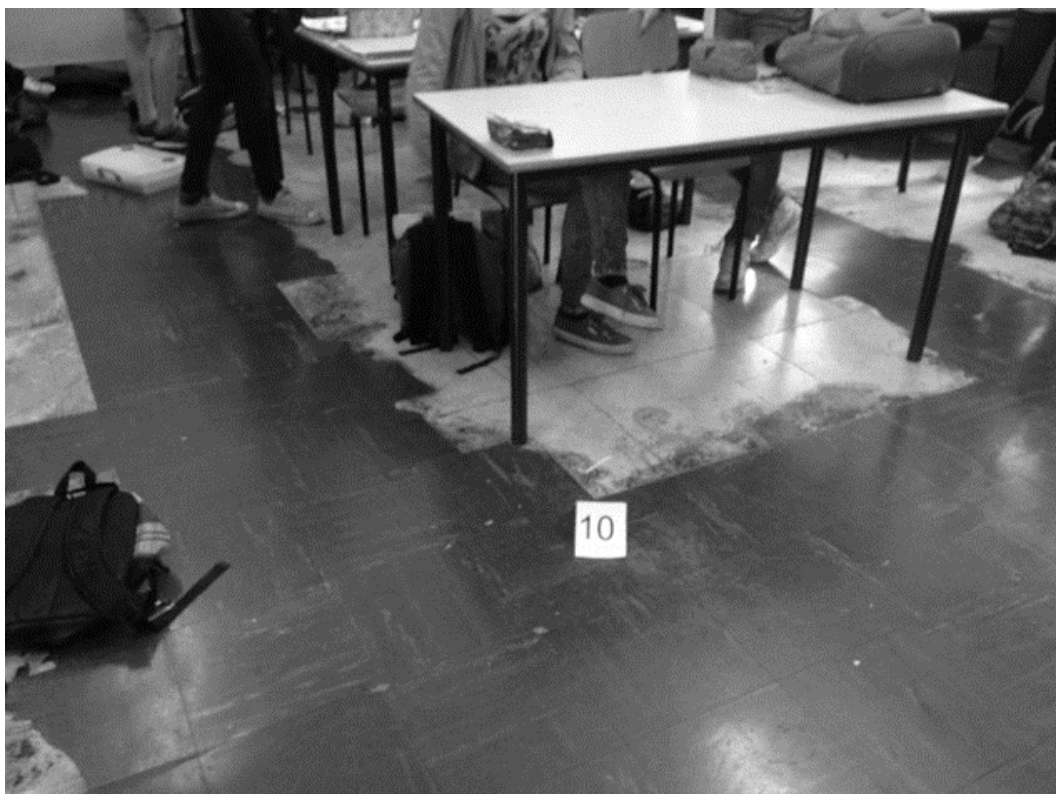

Fig. 4. Asbestos vinyl floors of a playtime classroom (a) and classroom (b) heavily damaged.

(a)

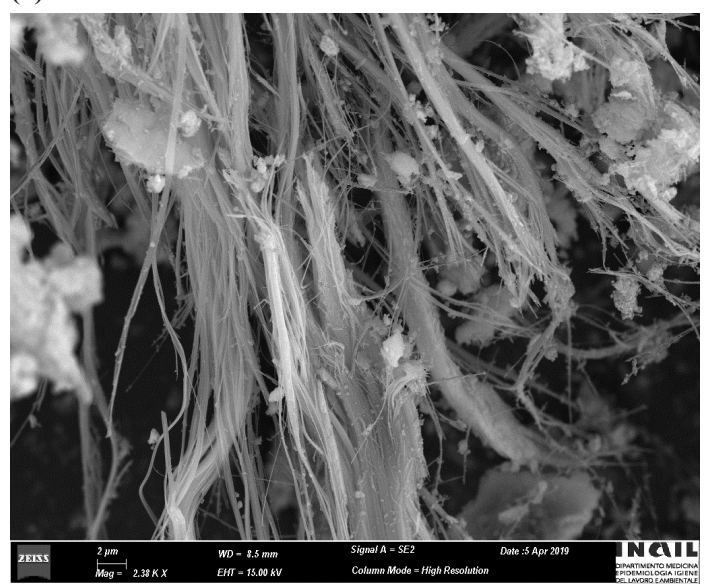

(b)

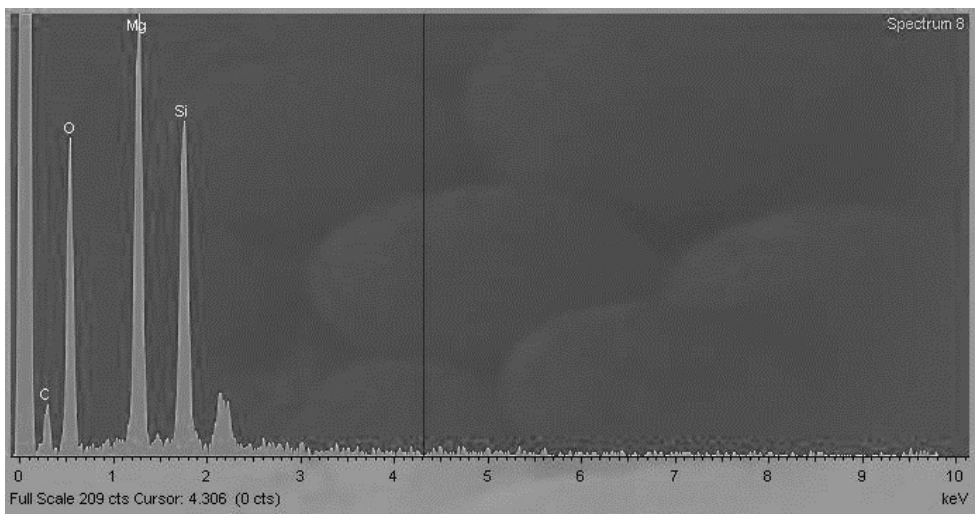

Fig. 5. SEM image of chrysotile (a) in vinyl-asbestos tiles with EDS analysis (b).

rooms where deteriorated vinyl-asbestos floor tiles were present. During the sampling, the schools were in operation and normal student activity took place, in order to obtain representative data concerning the exposure which people are subjected in real situations.

As expected, the concentration of airborne asbestos fibres was always lower than the detection limit, that is the limit below which, for the Poisson distribution, with 95\% probability, the actual concentration must lie when no fibre is found during SEM analysis. A detection limit of $0.3 \mathrm{f} / 1$ was assumed on the basis of $1 \mathrm{~mm}^{2}$ of analyzed filter area and a sample air volume of 3,000 1 .

\section{Discussion}

Three forms of asbestos were found in surveyed school buildings: 1. fireproofing materials; 2 . insulation on pipe, boilers and ducts; 3. miscellaneous forms such as wallboard, roofs and floor tiles. Materials in the first two categories are friable while materials in the third category are non-friable.

Friable ACM usually contain high levels of asbestos (up to $100 \%$ in some cases). If disturbed, friable asbestos products pose a greater risk to health because the asbestos fibres can get into the air very easily.

On the contrary, non-friable ACM contain around 15\% 
(a)

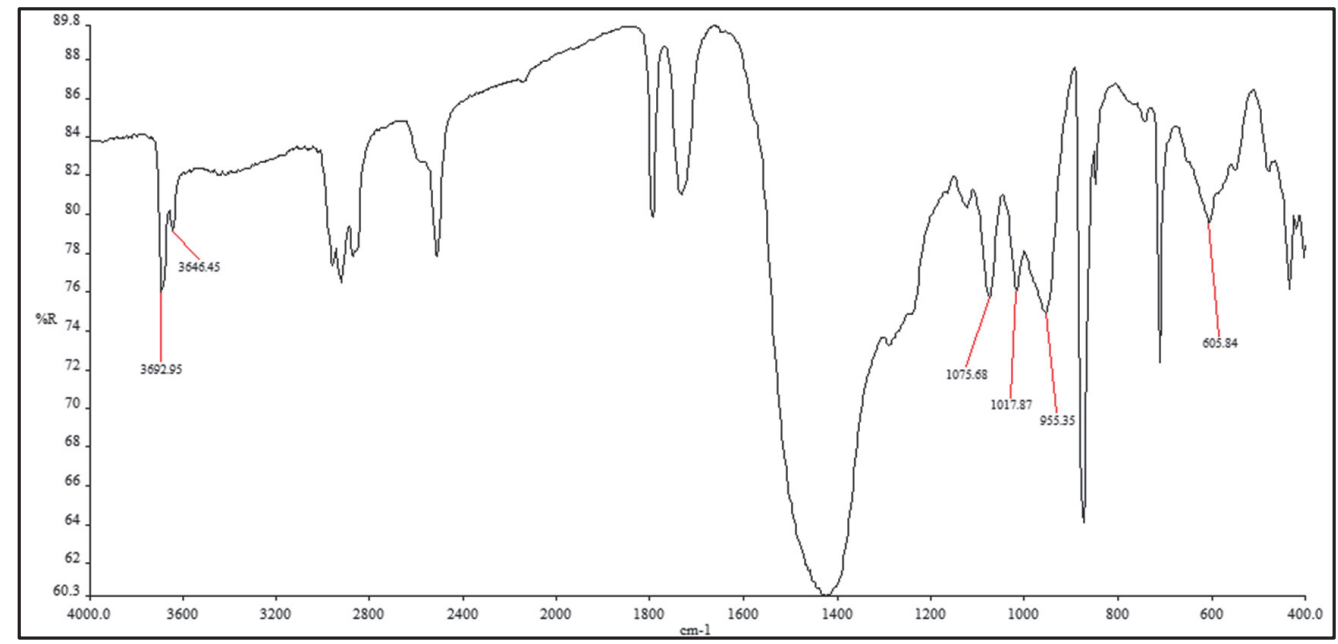

(b)

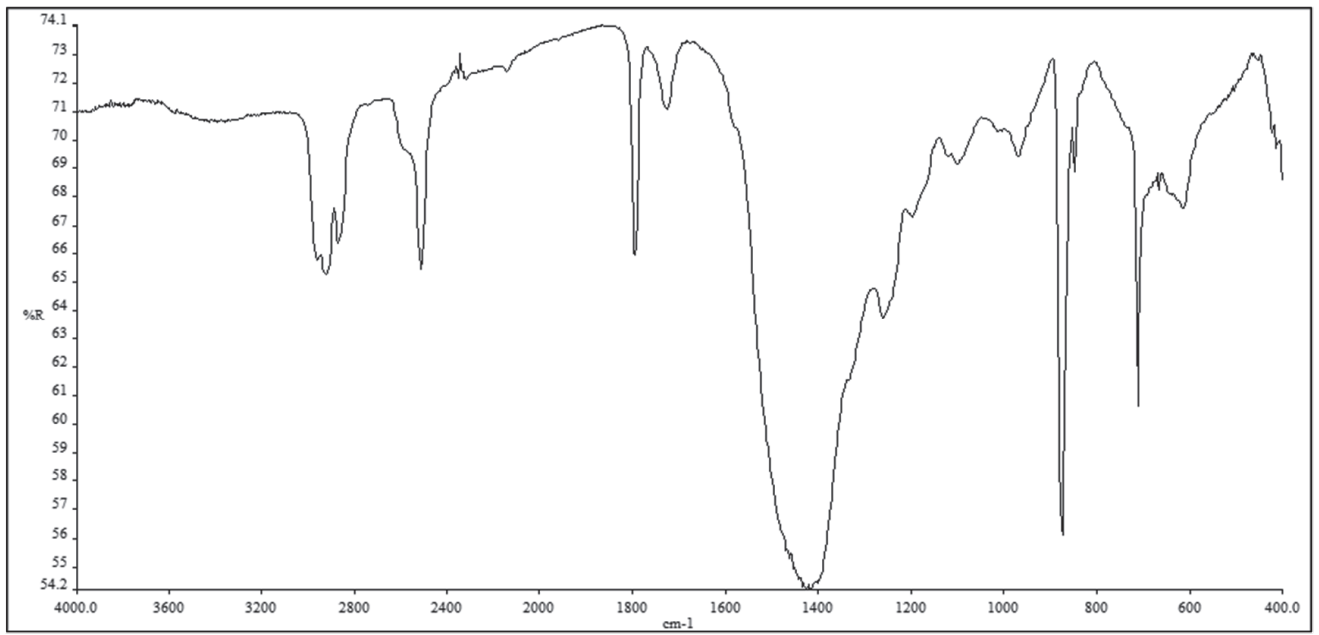

Fig. 6. IR spectra: absorption bands of chrysotile in vinyl sample (a) and IR absorption bands of vinyl matrix in sample without chrysotile (b).

(a)

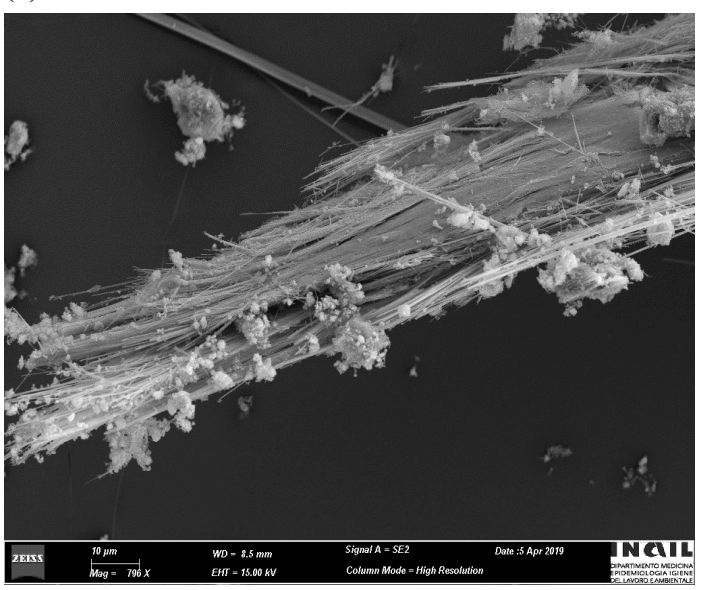

(b)

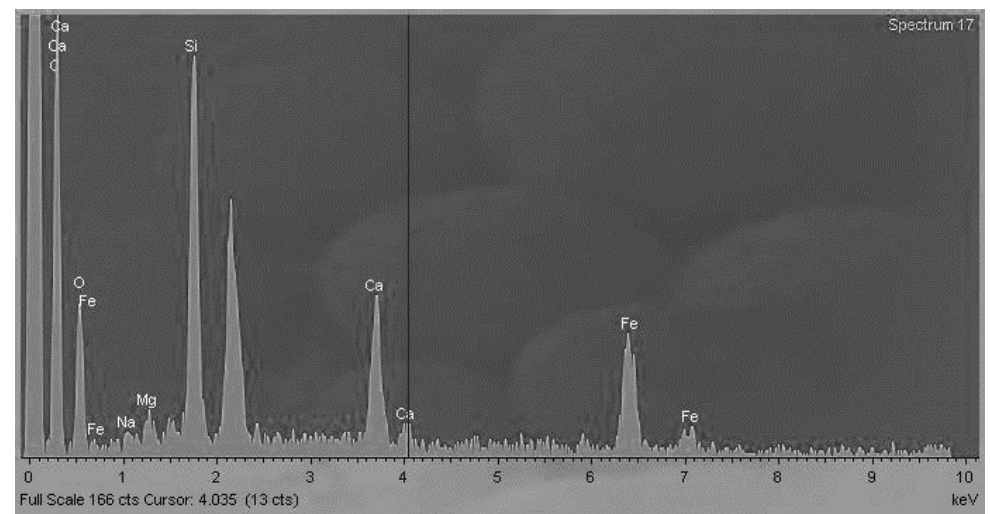

Fig. 7. SEM image of crocidolite (a) in asbestos-cement roofs with EDS analysis (b). 
Table 3. Estimated amount of ACM in the surveyed schools

\begin{tabular}{lccc}
\hline Non-friable ACM & ACM total amount & $\begin{array}{c}\text { ACM average amount per } \\
\text { school }\end{array}$ & ACM maximum amount \\
\hline Water tanks & 30 ton & $180 \mathrm{~kg}$ & $1,400 \mathrm{~kg}$ \\
Vinyl floors & $5,000 \mathrm{~m}^{2}$ & $30 \mathrm{~m}^{2}$ & $500 \mathrm{~m}^{2}$ \\
Roofs & $\begin{array}{c}150,000 \mathrm{~m}^{2} \text { corresponding to } \\
\text { about } 1,950 \text { ton }\end{array}$ & $\begin{array}{c}900 \mathrm{~m}^{2} \text { corresponding to } \\
\text { about } 12 \text { ton }\end{array}$ & $3,000 \mathrm{~m}^{2}$ corresponding about 40 \\
& ton
\end{tabular}

Table 4. Percentage of asbestos-cement materials found in surveyed schools according to damage classes

\begin{tabular}{ccc}
\hline $\begin{array}{c}\text { Intact materials } \\
(\mathbf{\%})\end{array}$ & $\begin{array}{c}\text { Material susceptible to damage } \\
(\mathbf{\%})\end{array}$ & $\begin{array}{c}\text { Damaged materials } \\
\mathbf{( \% )}\end{array}$ \\
\hline- & - & Water tanks $(100 \%)$ \\
- & - & Flues and chimneys $(100 \%)$ \\
- & Asbestos-cement roofs $(10 \%)$ & Asbestos-cement roofs $(90 \%)$ \\
- & Downpipes and gutters $(40 \%)$ & Downpipes and gutters $(60 \%)$ \\
- & Acoustic panels $(100 \%)$ & - \\
\hline
\end{tabular}

of asbestos locked inside a bonding compound such as cement. If they are in good repair do not constitute a significant source of airborne asbestos fibres.

Most of the ACM found in school buildings were non-friable materials: asbestos cement materials and vinyl floor tiles. The analysis by microscope showed that most of the cement materials presented chrysotile and crocidolite.

Among asbestos-cement materials, about $50 \%$ is represented by water tanks, no longer used, that were in closed rooms not accessible to students and school staff. On average, these materials did not show breakages or cracks, but observing the material carefully, an abundance of the asbestos fibres free from the matrix on the surface of the material was detected (Fig. 3b). The fibres are easily removable using tweezers and this is an indication of a very poor state of conservation.

Immediate removal was not recommended as these materials were located in a closed room away from the student and school staff, however it was recommended to schedule their removal.

School managers need to carry out asbestos risk assessments. They should ensure risks are managed by checking on the presence and state of asbestos in their schools. Where necessary, they should remove asbestos according to the regulations. The method of control that is selected (removal, encapsulation, or enclosure) must be appropriate for the type of material involved and its location. As an example, an encapsulant is not appropriate when the sprayed asbestos material is not firmly bonded to its structural support. On the contrary, it is recommended on roofing materials as long as they be able to withstand the addi- tional weight of the encapsulant applied to the roof

The asbestos-cement roofing sheets are subject to deterioration because of the exposure to atmospheric agents. In the long run the action of water, sun, ice, wind, moss and lichen, or of pollutants such as sulphur dioxide, can cause corrosion that facilitates the gradual release of asbestos fibres (Fig. 3a).

An important role is the visual survey of the roofing sheet surface for assessing the corrosion of ACM and allowing the choice of action to be undertaken in face of ACM. Generally, the choice is made by coupling the visual survey with air samplings in order to verify to release of asbestos fibres. In surveyed schools, outdoor ambient air samplings did not carry out because experience has taught us that in situations of advanced state of deterioration of asbestos-cement roofs, a release of asbestos fibres was not observed $^{16)}$ and when the release was present, it was always below the values proposed by World Health Organization (WHO) in urban areas. WHO gives reference data for pollution by asbestos. In rural areas, i.e., in spot far away from sources of emission by human activity, the concentrations are less than $0.1 \mathrm{f} / 1$, while in urban areas the pollution levels vary from values lower than $0.1 \mathrm{f} / \mathrm{l}$ up to approximately 1 $\mathrm{f} / 1$, the latter corresponding to areas with heavy traffic ${ }^{17)}$. However, most of the asbestos-cement sheets found in the schools were degraded and their removal was recommended.

An important category of ACM is vinyl floor tiles. About $10 \%$ of the surveyed school buildings had vinyl-asbestos floor tiles. The size of floor tiles was $20 \mathrm{~cm}, 30 \mathrm{~cm}$, or 45 $\mathrm{cm}$ squares. The most frequent size was $20 \mathrm{~cm}$, however 
(a)

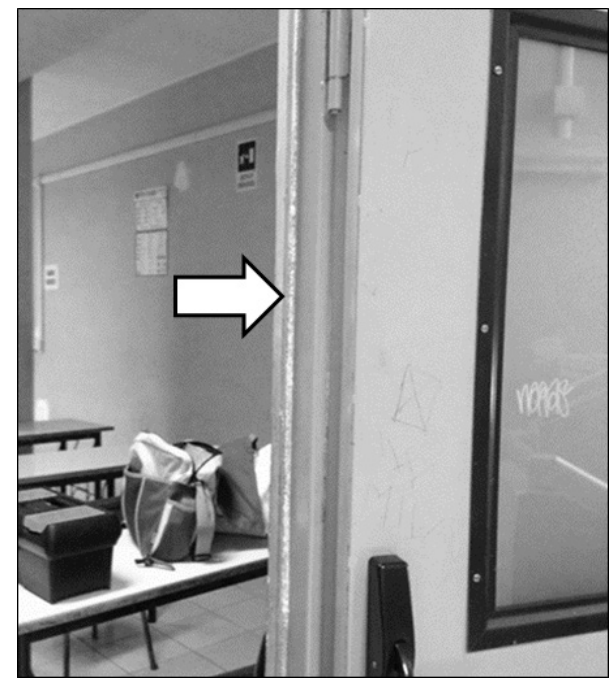

(b)

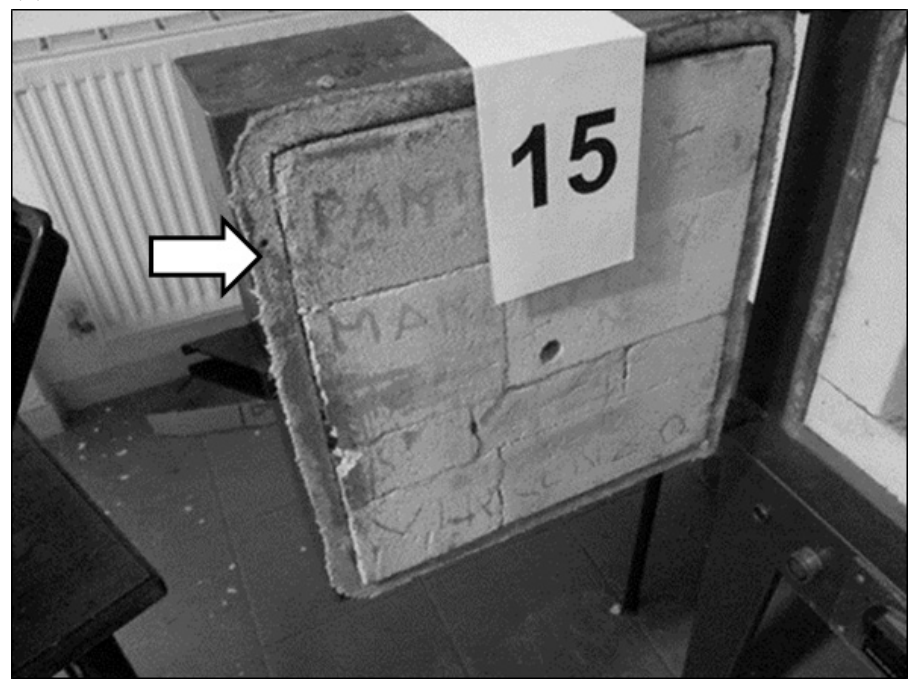

Fig. 8. Examples of friable ACM: lining of chrysotile in fire-rated door (a) and asbestos insulation lining in a laboratory oven (b).

(a)

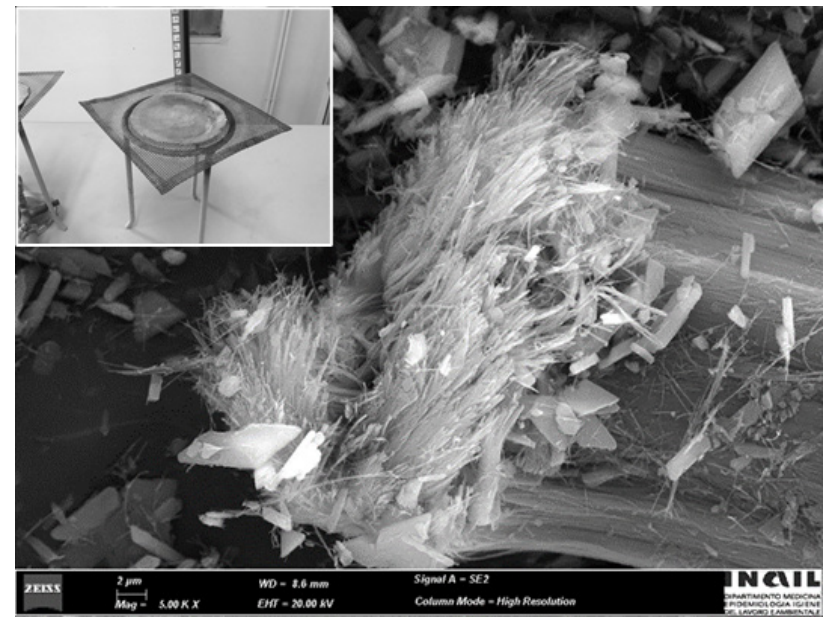

(b)

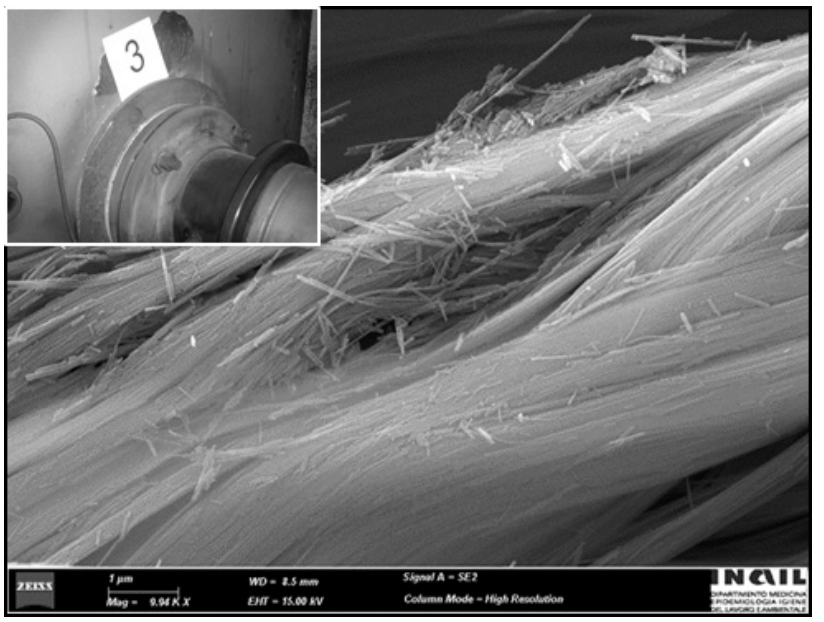

Fig. 9. SEM images of chrysotile: heat-resistant pad of Bunsen burner gauze mat used in science classrooms (a); thermal insulation on boilers (b).

the two bigger sizes were found in some schools. The asbestos contained in the tiles is firmly bound in the vinyl matrix. These materials are unlikely to release measurable levels of asbestos fibre into the airborne environment if they are left undisturbed.

Unfortunately, many asbestos floor tiles were stuck to the floor screed with a black bitumastic adhesive which in also contained asbestos. With the asbestos floor tiles removed what they are left with is a black sticky mess which still contains asbestos. The school bags put on the floor were likely to carry dust containing asbestos.

Despite the vinyl tiles are considered non-friable, in these conditions floor tiles become friable material. In most cases, when the vinyl tiles are not excessively damaged, it is better off leaving the asbestos floor tiles in place and overlaying with new flooring. On the contrary, measures that remove the floor must be taken immediately when there are damaged floors like those shown in Fig. 4.

As expected, air samplings carried out during normal activity took place in classrooms with damaged vinyl tiles did not detect airborne asbestos fibres. Should be considered that an air sampling measures current condition without giving information on a possible fibres release in the past and/or in the future. The analysis of settled dust showed few asbestos fibres in two schools having vinyl floor tiles severely damaged, confirming a release of asbestos from 
ACM.

A final report was drafted in which the risks and hazards to the health of student and school staff were highlighted. The headteacher decided to remove asbestos during the summer vacation when the schools were closed. Waiting for asbestos removal, partial overlay with new tiles was made.

Finally, measures to prevent or reduce asbestos hazards were applied in the school where external walls were in asbestos-cement. Do not cut or make fixings, do not stick drawing pins into and do not drill into without proper authority and precautions were some of the simple prevention measures.

The survey carried out in schools of Rome allowed to develop, among headteachers, the awareness of the asbestos health hazard and the need to manage these hazards appropriately. About the friable material found in 9 schools, school board of all schools immediately removed the old ovens and Bunsen burner gauze mat containing asbestos were disposed of as hazardous waste. Up to now, no schools has removed tanks and /or roofing; and 5 schools have completed asbestos abatement, removing damaged vinyl floors. Public Institutions to which the authors of this work belong encourage asbestos removal as preferred abatement method due to the long time that a child stays at school.

If there is non-friable asbestos in a school, it must be inspected on a regular basis waiting to be removed during summer months. Unfortunately, asbestos removal is usually a last resort because of high costs and public concern and anxiety will prevail as long as Italian schools have limited funding for safety inspections. In this regard, a policy of openness sharing correct information about asbestos management plan with teachers, students, staff, and parents is strongly recommended. In the past, headteachers often responded to pressure from parent groups ineffectively.

The widespread use of asbestos in school buildings and insufficient funds to resolve the problem makes it necessary for the government to establish the timetable and priorities for action on removal of asbestos from all schools, ensuring the safety of students, teachers and staff. The cost of dealing with ACM may be high, but this should not be an excuse for ignoring the problem.

We believe that this study represents the beginning of a larger study that leads to national knowledge of how many asbestos materials are present in public and private schools.

\section{Funding}

This work does not receive funding in any form.

\section{Conflict of Interest}

The authors declare no conflict of interest.

\section{References}

1) Circular of Italian Ministry of Health 1 July 1986, n. 42. Indicazioni esplicative per l'applicazione dell'ordinanza ministeriale 26 giugno 1986 relativa alle restrizioni sul mercato ed all'uso della crocidolite e di taluni prodotti che la contengono (in Italian).

2) Italian Parliament Law n. 257, 27 March 1992. Norms regarding the discontinuance of the utilization of asbestos. Italian Official Journal n. 64, 13 April 1992 (in Italian).

3) Environmental Protection Agency (EPA) 1998 Terms of Environment (rev. ed. EPA 175-B-97-001). Washington, D.C.: EPA.

4) Kang D, Myung MS, Kim YK, Kim JE (2013) Systematic review of the effects of asbestos exposure on the risk of cancer between children and adults. Ann Occup Environ Med 25, 10.

5) Kim JJ (2004) Ambient Air Pollution: Health Hazards to Children. Pediatrics 114, 1699-707.

6) Noncancer Reference Exposure Levels (2008) California EPA Air Toxicology and Epidemiology Branch Office of Environmental Health Hazard Assessment. https:/oehha. ca.gov/media/downloads/crnr/noncancertsdfinal.pdf. Accessed September 13, 2021.

7) Phalen RF, Oldham MJ, Beaucage CB, Crocker TT, Mortensen JD (1985) Postnatal enlargement of human tracheobronchial airways and implications for particle deposition. Anat Rec 212, 368-80.

8) American Academy of Pediatrics (1987) Committee on Environmental Hazards: asbestos exposure in schools. Pediatrics 79, 301-5.

9) Campopiano A, Casciardi S, Fioravanti F, Ramires D (2004) Airborne asbestos levels in school buildings in Italy. J Occup Environ Hyg 1, 256-61.

10) ReNaM (Italian national mesothelioma registry) VI Report (2018). https://www.inail.it/cs/internet/docs/alg-pubblregistro-nazionale-mesoteliomi-6-rapporto.pdf (in Italian). Accessed September 13, 2021.

11) Fazzo L, Minelli G, Bruno C, Comba P, Conti S, De Santis M, Zona A, Binazzi A, Magnani C, Marinaccio A, Iavarone I (2020) Early mortality from malignant mesothelioma in Italy as a proxy of environmental exposure to asbestos in children. Ann Ist Super Sanita 56, 478-86.

12) Italian Ministry of Health Decree of the 6th of Sepetember 1996. Normative e metodologie tecniche per la valutazione del rischio, il controllo, la manutenzione e la bonifica di materiali contenenti amianto presenti nelle strutture edilizie. Gazzetta Ufficiale 10 dicembre1994 n.288, Serie generale (in Italian).

13) Italian Decree of Ministry of Industry, Commerce and 
Crafts 12 February 1997. Criteri per l'omologazione dei prodotti sostitutivi dell'amianto. Gazzetta Ufficiale 13 marzo 1997, n. 60, Serie generale (in Italian).

14) Occupational Safety and Health Administration (OSHA) 2002 Asbestos standard for the construction industry. OSHA 3096, 2002 (Revised). https://www.osha.gov/ Publications/osha3096.pdf. Accessed September 13, 2021.

15) Environmental Protection Agency (EPA). Guide to the Householders Asbestos Disposal Scheme (HADS) in the Shoalhaven 2014/15. https://doc.shoalhaven.nsw.gov.au/ Displaydoc.aspx?Record=d14/164375. Accessed September
13, 2021.

16) Fiumi L, Campopiano A, Casciardi S, Ramires D (20012) Method validation for the identification of asbestos-cement roofing. Appl Geomat 4, 55-64.

17) World Health Organization (WHO) 2000 Air quality guidelines for Europe, 2nd edition. WHO Regional Publications, European Series, No. 91. https://apps.who.int/ iris/bitstream/handle/10665/107335/9789289013581-eng. pdf? sequence $=1 \&$ isAllowed=y. Accessed September 13, 2021. 